\title{
Changes in the activity of 'active' pyruvate dehydrogenase complex in the newborn of normal and diabetic rats
}

\author{
C. I. Chitra, J.M.Cuezva and M.S. Patel \\ Departments of Biochemistry and Nutrition, Case Western Reserve University School of Medicine, Cleveland, Ohio, USA
}

\begin{abstract}
Summary. At birth, hepatic 'active' and 'dichloracetate-activated' pyruvate dehydrogenase complex activities in the newborn of normal, mildly diabetic, and severely diabetic rats were similar. The 'active' and 'dichloracetate-activated' pyruvate dehydrogenase complex activities increased significantly during the first 2 and 6 postnatal $\mathrm{h}$, respectively in the three groups of neonates $(p<0.05)$. The greatest increase in both 'active' and 'dichloroacetate-activated' pyruvate dehydrogenase complex activity was observed in the neonates of mildly diabetic rats. Administration of glucose or insulin at birth to the newborn of normal rats caused a significant increase in the
\end{abstract}

percentage of 'active' pyruvate dehydrogenase complex activity within $1 \mathrm{~h}(p<0.01)$. Similar treatment caused no significant increases in the newborn of severely diabetic rats. The transient increases in 'active' pyruvate dehydrogenase complex activity in the neonates of normal and diabetic rats were consistent with rapid disappearance of blood lactate during the first hours of postnatal life.

Key words: Rat, hepatic pyruvate dehydrogenase complex, blood lactate, glucose, insulin.
Pyruvate dehydrogenase complex (PDC) catalyzes the formation of acetyl-CoA from pyruvate and hence allows further metabolism of pyruvate in the tricarboxylic acid cycle. PDC is regulated by a phosphorylation-dephosphorylation mechanism and by acetyl-CoA:CoA and $\mathrm{NADH}: \mathrm{NAD}^{+}$ratios $[1,3]$. Phosphorylation of the pyruvate dehydrogenase component of PDC by pyruvate dehydrogenase kinase renders it inactive whereas dephosphorylation by a specific phosphatase restores its catalytic activity $[1,4]$.

PDC activity is low in fetal rat liver but increases during the suckling period [5]. However, this finding is not supported by other studies $[6,7]$. Although the concentrations of plasma insulin, glucose and lactate in the newborn rat change markedly during the first few postnatal hours $[8,9]$, very little is known about possible changes in 'active' and 'total' hepatic PDC activity in the newborn rat during the immediate postnatal period. It has been shown that newborns of insulin-treated diabetic (mildly hyperglycaemic) rats experience a prolonged hypoglycaemia due to a delay in the onset of glycogenolysis [9] and gluconeogenesis [10] during the first few postnatal hours. The concentration of blood lactate in the newborn rat decreases from $8-10 \mathrm{mmol} / 1$ at birth to approximately $2 \mathrm{mmol} / \mathrm{l}$ at age $2 \mathrm{~h}$. Since the rate of hepatic gluconeogenesis in the newborn rat is negligible [11, 12], the fate of lactate in the newborn rat during the first few hours of life has been proposed to be oxidation $[12,13]$. In order to evaluate the possible role of PDC in lactate metabolism during the first six postnatal hours, we studied the changes in the activity of both 'active' and 'dichloracetate-activated' PDC in the newborn of normal, mildly diabetic, and severely diabetic rats. The effect of glucose or insulin administration at birth on the changes in 'active' PDC activity in newborn of normal and diabetic rats is also reported.

\section{Materials and methods}

\begin{abstract}
Animals
Diabetes mellitus was induced in Sprague-Dawley rats (Charles River Breeding Laboratories, Wilmington, Massachusetts, USA) on day 5 of gestation by injecting streptozotocin ( 38 or $45 \mathrm{mg} / \mathrm{kg}$ body weight in $50 \mathrm{mmol} / 1$ sodium citrate buffer, $\mathrm{pH} 4.5$ ) into the tail vein [9]. A blood sample $(25 \mu \mathrm{l})$ was obtained from the tail vein $48 \mathrm{~h}$ after the injection, and thereafter three additional blood samples were drawn at 5 day intervals. The mean of four blood glucose determinations from days 7 to 22 of gestation was taken as the average blood glucose level for each diabetic pregnant rat [9]. The mean blood glucose levels from days 7 to 22 of gestation for normal, mildly and severely diabetic rats were $4.5 \pm 0.2(n=16), 7.4 \pm 0.3(n=10)$ and $19.6 \pm 0.6 \mathrm{mmol} / \mathrm{l}(n=16)$, respectively. In the present study, we induced and maintained mild hy-
\end{abstract}


perglycaemia in pregnant rats from days 7 to 22 by injecting $38 \mathrm{mg}$ streptozotocin $/ \mathrm{kg}$ body weight. Many characteristic findings observed in newborn of the insulin-treated diabetic rats (macrosomia, postnatal hyperinsulinaemia, hypoglucagonaemia and prolonged lowered plasma glucose) [9] were present also in the newborn of mildly diabetic rats (J.M.Cuezva and M.S. Patel, unpublished observations).

Pregnant rats from days 18 to 22 of gestation were killed by cervical dislocation and their fetuses were delivered by Caesarian section. Fetal livers were removed immediately and frozen in liquid nitrogen. Term fetuses were delivered rapidly by Caesarian section from 22-day-pregnant rats and placed in a humidicrib at $37^{\circ} \mathrm{C}$ as reported previously [9]. At appropriate time intervals, livers were removed from neonates (two pups from a litter per point) and frozen in liquid nitrogen. In one series, glucose $(0.111 \mathrm{mmol})$ or insulin $(10 \mathrm{mU}$ Iletin U-100 regular insulin, Eli Lilly, Indianapolis, Indiana, USA) in NaCl $(0.154 \mathrm{mmol} / 1)$ was injected intraperitoneally into the newborns; an equal volume of saline was injected into the control fetuses. Blood samples $(25 \mu \mathrm{l})$ were deproteinized, and glucose [14] and lactate [15] were measured in the supernatant.

\section{Enzyme assay}

Frozen liver was ground at liquid $\mathrm{N}_{2}$ temperature and the powder was weighed and homogenized in the potassium chloride medium [16]. A portion of the homogenate was frozen in liquid $\mathrm{N}_{2}$ and stored at $-20{ }^{\circ} \mathrm{C}$ until "active' PDC activity (dephosphorylated form) was assayed. For 'dichloracetate-activated' PDC activity, the inactive enzyme (phosphorylated form) was first converted to its 'active' form by incubating the homogenate containing $5 \mathrm{mmol} / 1$ dichloracetate, $15 \mathrm{mmol} / 1 \mathrm{MgCl}_{2}$ and $1 \mathrm{mmol} / 1 \mathrm{CaCl}_{2}$ at $30^{\circ} \mathrm{C}$ for $10 \mathrm{~min}$. The mixture was then frozen in liquid $\mathrm{N}_{2}$ and stored at $-20^{\circ} \mathrm{C}$. The samples were thawed immediately prior to assaying the activity. The activity of PDC was assayed by measuring the formation of ${ }^{14} \mathrm{CO}_{2}$ from $\left[1-{ }^{14} \mathrm{C}\right]$ pyruvate with a minor modification [17] of the procedure of Leiter et al. [16]. The assay mixture $(0.2 \mathrm{ml})$, contained potassium phosphate $(50 \mathrm{mmol} / 1 \mathrm{pH} 8.0)$, sodium $\left[1-{ }^{14} \mathrm{C}\right]$ pyruvate $(0.5 \mathrm{mmol} / 1$ sp. act. $100 \mathrm{dpm} / \mathrm{nmol}$ in the mixture; New England Nuclear corporation, Boston, Mass., USA), $\mathbf{M g C l}_{2}(2 \mathrm{mmol} / 1)$, thiamine pyrophosphate $(0.1 \mathrm{mmol} / 1), \mathrm{NAD}^{+}(2.5 \mathrm{mmol} / 1)$, dithiothreitol $(1 \mathrm{mmol} / 1)$, coenzyme A $(0.5 \mathrm{mmol} / \mathrm{l})$ and phosphotransacetylase $(1 \mu \mathrm{g} / \mathrm{ml})$ [16]. The reaction was started by adding the homogenate $(10-20 \mu \mathrm{l})$. After $4 \mathrm{~min}$ [17], the reaction was terminated by adding $0.05 \mathrm{~N} \mathrm{H}_{2} \mathrm{SO}_{4}(50 \mu \mathrm{l})$ from a syringe inserted through the stopper. After an additional $45 \mathrm{~min}$ of shaking to allow a complete diffusion of $\mathrm{CO}_{2}$ into hydroxide of hyamine- $10 \mathrm{X}$, radioactivity was determined [16]. Blank assays were run without the homogenate and also with acid-inactivated enzyme. In preliminary experiments, it was observed that the rate of pyruvate decarboxylation was linear for $6 \mathrm{~min}$ under the conditions described above; a 4 min-incubation was carried out in most experiments. The production of ${ }^{14} \mathrm{CO}_{2}$ was linear up to $20 \mu \mathrm{l}$ of liver preparation, and each sample was assayed in triplicate using two different volumes of the preparation. To determine the extent of maximum dephosphorylation (and hence activation of PDC), in the presence of dichloroacetate, we compared this treatment with exogenously added purified bovine kidney pyruvate dehydrogenase phosphate phosphatase $(0.88 \mathrm{U} / \mathrm{ml}$ of incubation medium). PDC activity was $(n=8) 267 \pm 20$ and $417 \pm 19 \mathrm{mU} / 100 \mathrm{mg}$ of protein in liver preparations (from 6-h-old normal newborn rats) treated with dichloroacetate and phosphatase, respectively. Similarly, PDC activity was $(n=5)$ $149 \pm 10$ and $252 \pm 11 \mathrm{mU} / 100 \mathrm{mg}$ of protein in liver preparations (from 6-h-old neonates of severely diabetic rats) treated with dichloroacetate and phosphatase, respectively. Dichloroacetate-activation of PDC represented $63.8 \pm 3.1 \%$ and $59.1 \pm 1.9 \%$ of 'total' (phosphataseactivated) PDC activity in neonates of normal and severely diabetic rats (NS). In this study, only 'dichloracetate-activated' PDC activity is reported. One unit of enzyme activity is defined as the oxidation of $1 \mu \mathrm{mol}$ of $\left[1-{ }^{14} \mathrm{C}\right]$-pyruvate/min at $30{ }^{\circ} \mathrm{C}$. Protein was measured by the method of Lowry et al. [18], using bovine serum albumin as standard.

\section{Statistical analysis}

Statistical analysis was performed using the Student's t-test. A $p$ value of 0.05 or less was taken as significant, and the results are expressed as mean \pm SEM.

\section{Results}

Although 'active' PDC activity in livers of normal rat fetuses decreased during the last 4 days of gestation, 'dichloroacetate-activated' PDC activity increased significantly in such livers $(p<0.05$; Fig. 1). Mild and severe maternal diabetes had no effect on the activities of 'active' and 'dichloroacetate-activated' PDC measured at term.

During the postnatal period, 'active' PDC activity increased about twofold in the newborn of normal rats within the first hour $(p<0.001)$, and slowly declined to the level observed at birth by $6 \mathrm{~h}$ (Fig. 1). During the first $6 \mathrm{~h}$ postnatal, hepatic 'active' PDC activity was maintained at a higher level in the neonates of mildly diabetic rats than in age-matched neonates of normal rats. The changes in 'active' PDC activity in livers of neonates of severely diabetic rats followed a pattern which was similar to that observed in neonates of normal rats. 'Dichloroacetate-activated' hepatic PDC activity in newborns of normal rats increased significantly during the first $3 \mathrm{~h}$ postnatal $(p<0.001)$. Although there was a delay in the initial increase in 'dichloroacetate-activated' PDC activity in livers of neonates of both mildly and severely diabetic rats, these neonates achieved the same level of enzyme activity at age $2 \mathrm{~h}$. Further increases in 'dichloroacetate-activated' PDC activity were observed only in the livers of neonates of normal $(p<0.05)$ and mildly $(p<0.01)$ diabetic rats (Fig. 1). When these results were expressed as PDC activity $/ 100 \mathrm{mg}$ liver protein, the developmental pattern in the three groups of neonates remained essentially the same as shown in Figure 1 (results not shown).

The proportion of PDC in its 'active' form increased significantly in livers of all three groups of neonates within $1 \mathrm{~h}$ after birth $(p<0.01)$. In the neonates of mildly diabetic rats, approximately $45 \%$ of 'dichloroacetateactivated' PDC activity was in the 'active' form at age 1 and $2 \mathrm{~h}(p<0.05$, compared with normal neonates; Fig. 1).

Blood lactate concentrations in newborns of normal and diabetic rats were similar at birth. The blood lactate concentrations in neonates of both normal and mildly diabetic rats declined markedly during the first $2 \mathrm{~h}$ postnatal, and subsequently remained unchanged during the rest of the experimental period (Fig. 2). In contrast, a marked increase in blood lactate concentration was observed in neonates of severely diabetic rats $1 \mathrm{~h}$ after birth, followed by a precipitous decline during the second postnatal hour. Thereafter a slow decline to the normal level was observed by $6 \mathrm{~h}$ postnatal (Fig. 2). 


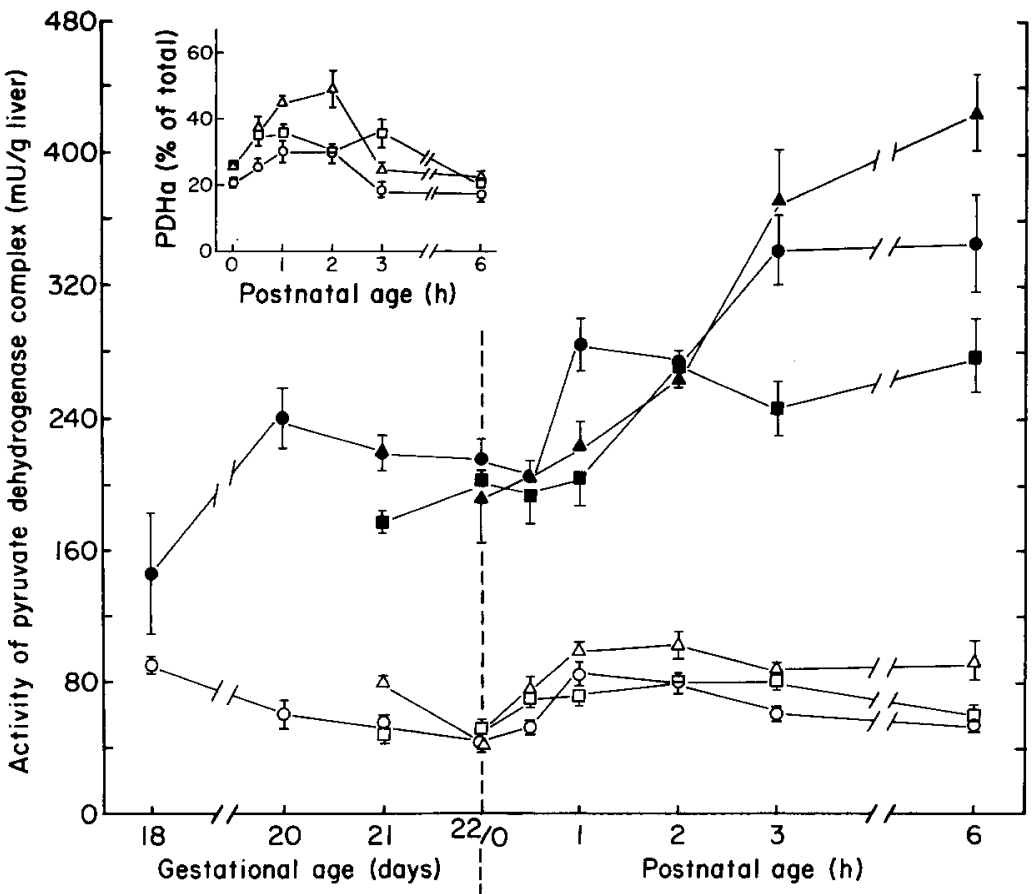

Fig. 1. Hepatic 'active' (open symbols) and 'dichloroacetate-activated' (closed symbols) PDC activity in the fetuses and neonates of normal $(O, 0)$, mildly diabetic $(\Delta, \Delta)$ and severely diabetic $(\square, \mathbf{\square})$ rats during the first 6 postnatal h. Inset: shows the changes in the percentage 'active' PDC (PDHa) of 'dichloroacetate-activated' PDC activity. The results are mean \pm SEM for four to 12 fetuses or neonates

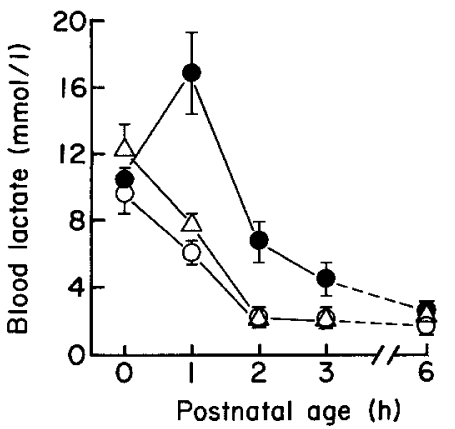

Fig. 2. Blood lactate concentrations in the neonates of normal $(O)$, mildly diabetic $(\Delta)$ and severely diabetic $(\bullet)$ rats during the first 6 postnatal $h$. The results are mean $\pm S E M$ for six to ten neonates

To study the effect of glucose or insulin administration on the activity of hepatic PDC activity, the newborns of normal and severely diabetic rats were injected intraperitoneally with either $0.111 \mathrm{mmol}$ glucose or $10 \mathrm{mU}$ insulin immediately after delivery. Administration of glucose caused hyperglycaemia (18.3 \pm $0.4 \mathrm{mmol} / 1$ at $30 \mathrm{~min}$ which slowly declined to $4.9 \pm$ $0.3 \mathrm{mmol} / 1$ at age $2 \mathrm{~h}$ (Fig. $3 \mathrm{C}$ ). The injection of glucose or insulin caused a significant increase in 'active' PDC activity at age $1 \mathrm{~h}$ compared with age-matched salineinjected neonates $(p<0.005)$, Fig. $3 \mathrm{~A})$. The activities declined to those found in the control group at age $2 \mathrm{~h}$. Similar developmental changes were observed when these results were expressed per $100 \mathrm{mg}$ of liver protein (results not shown). Also, the percentage of 'active' PDC in livers of glucose- and insulin-injected neonates was significantly higher than in saline-injected neonates of normal rats at age $1 \mathrm{~h}$ only ( $p<0.01$; Fig. 3 B).

The mean blood glucose concentration in newborns of severely diabetic rats was $15.9 \pm 0.6 \mathrm{mmol} / 1$ and de- clined steadily to $3.6 \pm 0.7 \mathrm{mmol} / 1$ in saline-injected neonates over the first $2 \mathrm{~h}$ postnatal (Fig. 4C). Administration of insulin significantly enhanced the reduction in blood glucose concentrations over the same period $(p<0.05)$. Administration of glucose to the newborns of severely diabetic rats caused a significant increase in blood glucose concentration $(p<0.05)$, which declined steadily after the first postnatal hour (Fig. 4C). Administration of glucose to newborns of severely diabetic rats caused significant increases in both 'active' $(p<0.01)$ and 'dichloroacetate-activated' $(p<0.001)$ PDC activity in the first postnatal hour compared with saline-injected neonates (Fig. 4a). Administration of insulin also caused significant increases in 'active' $(p<0.05)$ and 'dichloroacetate-activated' $(p<0.025)$ PDC complex activity at $30 \mathrm{~min}$ and $1 \mathrm{~h}$ of age, respectively, compared with age-matched saline-injected neonates. At the end of the second postnatal hour 'active' and 'dichloroacetate-activated' PDC activities were similar in the three groups of neonates (Fig. 4A). Again, these developmental changes remained essentially similar when the results were expressed per $100 \mathrm{mg}$ liver protein (results not shown). The percentage 'active' PDC activity showed no significant differences in glucose- and insulin-injected neonates compared with age-matched saline injected neonates of severely diabetic rats (Fig. 4B).

\section{Discussion}

Conflicting results have been reported on the development of PDC activity in rat liver during the fetal and suckling period [5-7]. Knowles and Ballard [5] observed that 'total' PDC activity was low in fetal rat liver and increased slowly to the adult level over several weeks. Al- 


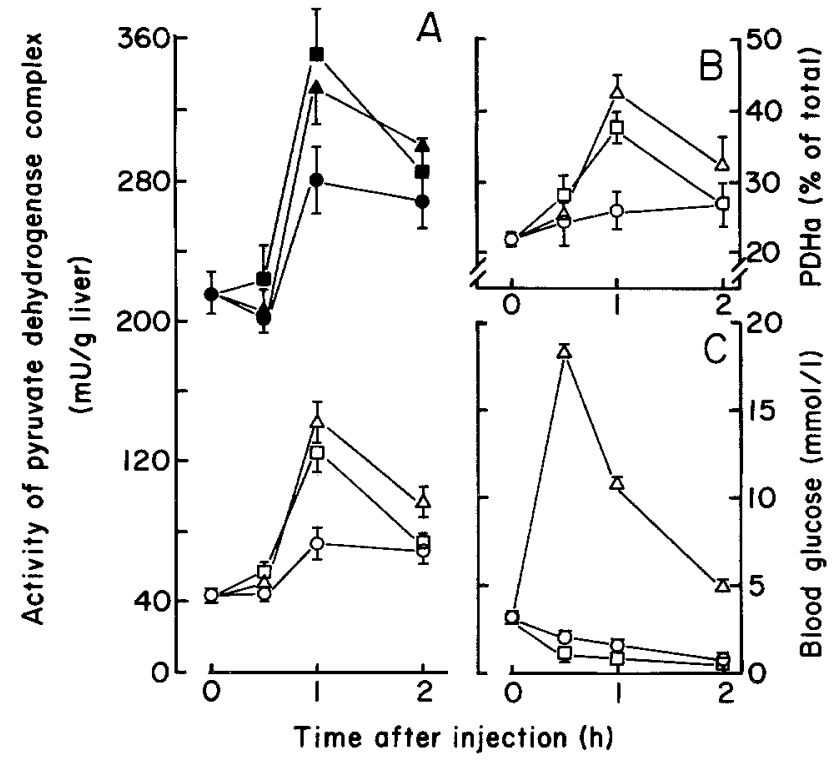

Fig.3A-C. Effect of saline $(O, \bullet)$, glucose $(\Delta, \Delta)$ and insulin $(\square$, घ) administration at birth on hepatic 'active' (open symbols) and 'dichloroacetate-activated' (closed symbols) PDC/activity (A) and blood glucose concentrations $(C)$ in the neonates of normal rats during the first 2 postnatal $h$. (B) shows the percentage 'active' PDC (PDHa) of 'dichloroacetate-activated' PDC activity. The results are mean \pm SEM for four to ten neonates

though Bailey et al. [6] reported an essentially similar developmental pattern for 'total' PDC activity in rat liver, they observed a marked reduction in 'total' PDC activity in livers of 1- to 3-day-old rats compared with fetal rats. In contrast, Kankel and Reinauer [7] reported no significant changes in 'total' PDC activity in livers from 17-day-old fetuses to 12-day-old suckling rats. In previous studies [5-7], the activation of inactive PDC was accomplished by incubating liver samples with high concentrations of magnesium chloride. In the present study, we used dichloroacetate to inhibit pyruvate dehydrogenase kinase, thereby allowing the endogenous pyruvate dehydrogenase phosphate phosphatase to activate PDC. Using purified bovine kidney pyruvate dehydrogenase phosphate phosphatase, we observed that dichloroacetate-activation gave rise to approximately $60 \%$ of 'total' PDC activity in livers of neonates of both normal and diabetic rats.

During the first 2 postnatal hours, glucose and lactate are the primary metabolic fuels in the unsuckled newborn rat; the concentrations of these two metabolites decline rapidly during this period [8]. Medina et al. [12] observed that the lactate pool in the newborn rat is rapidly oxidized during the first $2 \mathrm{~h}$ of life. Since the rate of gluconeogenesis from three-carbon precursors is very low in the rat immediately after birth [11], Medina et al. [12] suggested that pyruvate derived from lactate (and glucose) was largely oxidized via PDC. The increase in the proportion of PDC activity in its 'active' form in newborn rat liver during the first 2 postnatal $h$ observed in the present study is consistent with the rap-

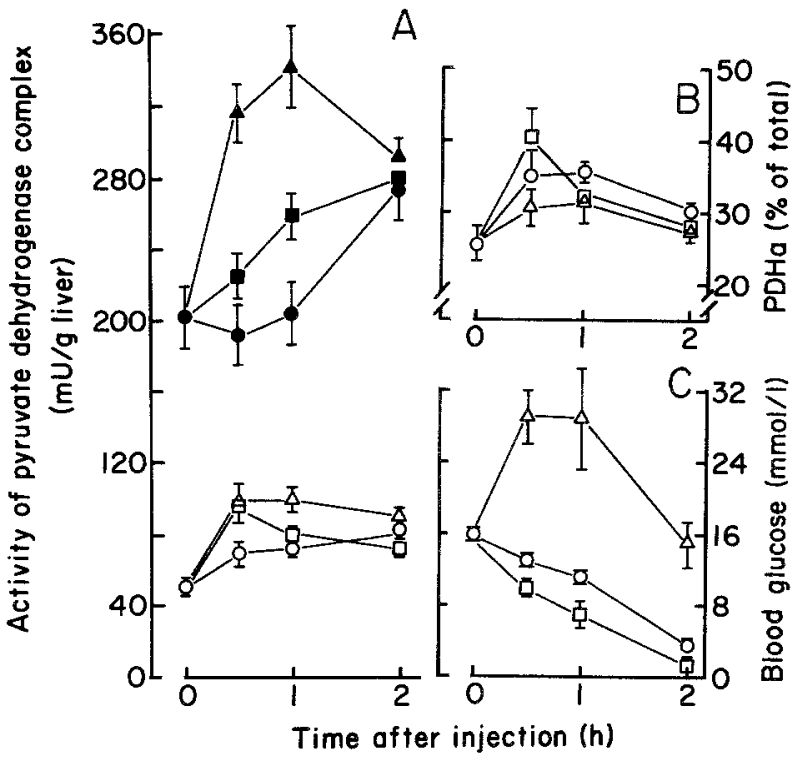

Fig.4A-C. Effect of saline $(O, O)$, glucose $(\Delta, \Delta)$ and insulin $(\square$, -) administration at birth on hepatic 'active' (open symbols) and 'dichloroacetate-activated' (closed symbols) PDC activity (A) and blood glucose concentrations (C) in the neonates of severely diabetic rats during the first 2 postnatal h. (B) shows the per cent 'active' PDC (PDHa) of 'dichloroacetate-activated' activity. The results are mean $\pm S E M$ for six to ten neonates

id oxidation of pyruvate derived from both glucose and lactate pools.

We recently observed that the concentrations of hepatic pyruvate in neonates of normal and diabetic rats increased approximately threefold within the first $h$ after birth [10]. Since pyruvate increases 'active' PDC activity by inhibiting the phosphorylation and concomitant inactivation of the pyruvate dehydrogenase component by its kinase [4], it is possible that the postnatal increase in hepatic pyruvate concentrations [10] may have enhanced the activity of 'active' PDC in neonates of both normal and diabetic rats. When glucose or insulin was administered to newborns of normal rats, there was a significant increase in 'active' PDC activity (Fig. $3 \mathrm{~A}$ ) and in the percentage 'active' PDC (Fig. $3 \mathrm{~B}$ ) in livers of these neonates. It is possible that the injection of glucose enhanced the secretion of insulin, and also increased the concentration of pyruvate derived from glucose. In contrast, the administration of glucose or insulin at birth to newborns of severely diabetic rats had very little effect on the proportion of PDC in its 'active' form compared with saline-injected neonates (Fig.4B). This is most likely due to higher concentrations of plasma glucose and insulin observed at birth in these newborns [9].

PDC activity is also regulated by changes in the $\mathrm{ATP} / \mathrm{ADP}$ ratio, $\mathrm{NADH} / \mathrm{NAD}^{+}$ratio and acetyl$\mathrm{CoA} / \mathrm{CoA}$ ratio as well as the concentrations of plasma insulin and non-esterified fatty acids [1-3]. No correlation was observed between the changes in 'active' PDC activity and $\mathrm{ATP} / \mathrm{ADP}$ ratio or $\mathrm{NADH} / \mathrm{NAD}^{+}$ratio in 
neonates of normal and diabetic rats during the first $6 \mathrm{~h}$ postnatal $[5,10$ and this study]. Since the concentrations of hepatic acetyl-CoA and CoA and also plasma nonesterified fatty acids were not measured in this study or previous studies [5-7], their possible influence on 'active' PDC cannot be evaluated in rat liver in the immediate postnatal period. Insulin is shown to regulate the level of 'active' PDC activity without altering the level of 'total' PDC activity in tissues from adult rats $[2,3]$. However, no correlation was observed between the changes in 'active' PDC in livers of neonates of normal and diabetic rats (this study) and their plasma insulin concentrations during the first $6 \mathrm{~h}$ postnatal $[9$, also our unpublished observations on neonates of mildly diabetic rats].

In summary, the transient increase in 'active' PDC activity in livers of neonates of normal and diabetic rats during the first $2 \mathrm{~h}$ of postnatal life is consistent with the rapid oxidation of the lactate body pool in the newborn rat. Changes in 'active' PDC activity are correlated with changes in the concentrations of hepatic pyruvate in these neonates during the first $6 \mathrm{~h}$ postnatal [10], suggesting that hepatic pyruvate concentration is an important regulator of hepatic PDC activity in rat neonates. These results suggest the importance of acute changes in 'active' PDC activity to enhance the oxidation of pyruvate derived from glucose and lactate, the two major metabolic fuels of the newborn rat during the immediate postnatal period.

Acknowledgements. This work was supported by HD 12643 and AM 20478 from the National Institutes of Health. J. M. C. was a postdoctoral fellow of the Spanish Ministry of Universities and Research. We wish to thank Dr. T.E. Roche, Kansas State University, Manhattan, Kansas, USA for providing purified bovine kidney pyruvate dehydrogenase phosphate phosphatase, and Mr. Lap Ho for carrying out phosphatase-activation studies.

\section{References}

1. Reed LJ (1974) Multienzyme complexes. Act Chem Res 7: 40-46 2. Denton RM, Randle PJ, Bridges BJ, Cooper RH, Kerbey AL, Pask HT, Severson DL, Stansbie D, Whitehouse S (1975) Regulation of mammalian pyruvate dehydrogenase. Mol Cell Biochem 9: $27-53$

3. Wieland $\mathrm{OH}$ (1983) The mammalian pyruvate dehydrogenase complex: structure and regulation. Rev Physiol Biochem Pharmacol 96: $123-170$

4. Linn TC, Pettit FH, Hucho F, Reed LJ (1969) $\alpha$-Keto acid dehydrogenase complexes, XI. Comparative studies of regulatory properties of the pyruvate dehydrogenase complexes from kidney, heart, and liver mitochondria. Proc Natl Acad Sci USA 64: 227-234

5. Knowles SE, Ballard FJ (1974) Pyruvate dehydrogenase activity in rat liver during development. Biol Neonate 24: 41-48

6. Bailey K, Hahn P, Palaty V (1976) Pyruvate dehydrogenase activity in liver and brown fat of the developing rat. Can J Biochem 54: 534-538

7. Kankel K-F, Reinauer H (1976) Activity of the pyruvate dehydrogenase complex in the mammary gland of normal and diabetic rats. Diabetologia 12: 149-154

8. Girard JR, Cuendet GS, Marliss EB, Kervran A, Rieutort M, Assan R (1973) Fuels, hormones, and liver metabolism at term and during the early postnatal period in the rat. J Clin Invest 52: $3190-3200$

9. Cuezva JM, Burkett ES, Kerr DS, Rodman HM, Patel MS (1982) The newborn of diabetic rat. I. Hormonal and metabolic changes in the postnatal period. Pediatr Res 16: 632-637

10. Cuezva JM, Chitra CI, Patel MS (1982) The newborn of diabetic rat. II. Impaired gluconeogenesis in the postnatal period. Pediatr Res 16: 638-643

11. Ballard FJ (1971) The development of gluconeogenesis in rat liver. Controlling factors in the newborn. Biochem J 124: 265-274

12. Medina JM, Cuezva JM, Mayor F (1980) Non-gluconeogenic fate of lactate during the early neonatal period in the rat. FEBS Letters 114: $132-134$

13. Arizmendi C, Medina JM (1983) Lactate as an oxidizable substrate for rat brain in vitro during the perinatal period. Biochem $\mathrm{J}$ 214: $633-635$

14. Bergmeyer HV, Bent E, Schmidt F, Stork H (1974) D-glucose determination with hexokinase and glucose-6-phosphate dehydrogenase. In: Bergmeyer HV (ed) Methods in enzymatic analysis, Vol.3. Academic Press, New York, pp 1196-1201

15. Gutmann I, Wahlefeld AW (1974) (+)-Lactate determination with lactate dehydrogenase and NAD. In: Bergmeyer HV (ed) Methods of enzymatic analysis, Vol.3. Academic Press, New York, pp 1464-1468

16. Leiter AB, Weinberg M, Isohashi F, Utter MF (1978) Relationship between phosphorylation and activity of pyruvate dehydrogenase in rat liver mitochondira and the absence of such a relationship for pyruvate carboxylase. J Biol Chem 253: 2716-2723

17. Sheu K-FR, Hu C-WC, Utter MF (1981) Pyruvate dehydrogenase complex activity in normal and deficient fibroblasts. J Clin Invest 67: 1463-1471

18. Lowry OH, Rosebrough NJ, Farr AL, Randall RJ (1951) Protein measurement with the Folin phenol reagent. J Biol Chem 193: $265-275$

Received: 16 April 1984

and in revised form: 11 December 1984

Dr. Mulchand S. Patel

Department of Biochemistry

Case Western Reserve University School of Medicine

2119 Abington Road

Cleveland, $\mathrm{OH} 44106$

USA 